Direct current shock therapy of cardiac arrhythmias was recently introduced by Lown, Amarasingham, and Neuman (1962). Shortly after, Oram et al. (1963) published their experience of this treatment in patients with atrial fibrillation. Further studies have followed, all testifying to the efficacy of electrical conversion of ectopic tachycardias to sinus rhythm (Bouvrain et al., 1963; Effert and Grosse-Brockhoff, 1963; Jouve et al., 1963; Killip, 1963; Lown et al., 1963; Reitman and DeArmas, 1963; Brown, Whitehead, and Morrow, 1964; Kuhn, 1964; Lown, 1964; Lown, Kleiger, and Wolff, 1964; Mathivat et al., 1964; McDonald, Resnekov, and O'Brien, 1964; Morris et al., 1964; Oram and Davies, 1964; Pantridge and Halmos, 1965). In the present paper we report on the immediate and late results we have obtained by this form of treatment in 170 patients. A detailed analysis of the electrocardiographic changes, especially the various types of cardiac arrhythmias occurring immediately after electric shock and their relation to concomitant drug therapy will follow as a separate communication.

\section{SuBJECTS AND METHOD}

The technique used was that described by Lown $e t$ al. (1962) and Oram et al. (1963). The rationale of the method is a complete depolarization of the heart by direct current electrical discharge enabling the sinus node to resume its activity. The apparatus used was a Corbin-Farnsworth defibrillator. The electrical discharge was synchronized to be delivered on the downslope of the $R$ wave of the electrocardiogram so as to avoid the vulnerable period in the cardiac cycle, which coincides with the apex of the $T$ wave. The energy employed varied between 80 and 300 watt-seconds. Premedication consisted of 0.2 to $0.4 \mathrm{mg}$. of scopolamine. Anæsthesia was induced with 200 to $400 \mathrm{mg}$. of sodium thiopentone and continued with nitrous oxide

Received June 17, 1965. and oxygen. Between December 1963 and March 1965 we have treated 200 episodes of ectopic tachycardia in 170 patients. Antiarrhythmic drugs such as quinidine, procaine amide, and propranolol (inderal) were given singly or in combination in the majority of the patients three to five days before electrical treatment, and after conversion to sinus rhythm in an attempt to prevent recurrences of the ectopic rhythm. Digitalis was used in all cases where indicated, but with increasing experience the dosage was reduced in the last 78 patients. Anticoagulants were given as a rule to patients who had atrial fibrillation associated with rheumatic heart disease, whether or not they had a history of systemic embolism. Many of these patients had already been on long-term anticoagulant prophylaxis; in others anticoagulants were started one to four weeks before direct current shock therapy.

\section{RESULTS}

The arrhythmias treated were atrial fibrillation, atrial flutter, atrial tachycardia, ventricular tachycardia, and ventricular fibrillation. The immediate results are summarized in Table $\mathrm{I}$.

Atrial Fibrillation. 170 episodes were treated in 145 patients. The underlying pathology was rheumatic heart disease in 117 patients, coronary artery disease in 14, congenital heart disease in 4 , thyrotoxicosis in 6 , chronic cor pulmonale in 1 , and "lone" atrial fibrillation in 3 patients. On 148 occasions $(87 \%)$ sinus rhythm was restored. Two illustrative electrocardiograms are shown in Fig. 1 and 2. Of the 22 failures, 18 were in the rheumatic group, one had congenital heart disease (patent ductus arteriosus in a 63-year-old woman with heart failure), one had chronic cor pulmonale, and 2 failures occurred in the group of 3 patients with "lone" atrial fibrillation. The average duration of atrial fibrillation was 2.3 years in the successful group 366 
TABLE I

DIRECT CURRENT SHOCK THERAPY OF CARDIAC ARRHYTHMIAS : IMMEDIATE RESULTS

\begin{tabular}{l|c|c|c}
\hline \multicolumn{1}{c|}{ Type of arrhythmia } & $\begin{array}{c}\text { No. of } \\
\text { episodes } \\
\text { treated }\end{array}$ & \multicolumn{2}{|c}{ Results } \\
\cline { 4 - 4 } & $\begin{array}{c}\text { Sinus rhythm } \\
\text { restored }\end{array}$ & $\begin{array}{c}\text { Ectopic rhythm } \\
\text { persisted }\end{array}$ \\
\hline Atrial fibrillation & 170 & 148 & 22 \\
Atrial flutter & 15 & 15 & 0 \\
Atrial tachycardia & 9 & 9 & 0 \\
Ventricular tachycardia & 4 & 3 & 1 \\
Ventricular fibrillation & 2 & 2 & 0 \\
\hline Total & 200 & 177 & 23 \\
\hline
\end{tabular}

average age was 44 years in the former and 46 years in the latter group. The immediate results in relation to the duration of atrial fibrillation before treatment are summarized in Table II.

Covering a follow-up period of up to 15 months, recurrences of atrial fibrillation occurred in 60 per cent of the immediate successes. Details of the recurrence rate are shown in Table III. In 24 cases
TABLE II

ATRIAL DEFIBRILLATION BY DIRECT CURRENT SHOCK THERAPY IMMEDIATE RESULTS IN RELATION TO DURATION OF ATRIAL FIBRILLATION

\begin{tabular}{|c|c|c|c|}
\hline \multirow[b]{2}{*}{$\begin{array}{l}\text { Duration of atrial } \\
\text { fibrillation }\end{array}$} & \multirow{2}{*}{$\begin{array}{c}\text { No. of } \\
\text { episodes } \\
\text { treated }\end{array}$} & \multicolumn{2}{|c|}{ Results } \\
\hline & & $\begin{array}{c}\text { Sinus rhythm } \\
\text { restored }\end{array}$ & $\begin{array}{c}\text { Un- } \\
\text { changed }\end{array}$ \\
\hline $\begin{array}{l}<1 \text { year } \\
>1 \text { year }\end{array}$ & $\begin{array}{r}60 \\
110\end{array}$ & $\begin{array}{l}59 \\
89\end{array}$ & $\begin{array}{r}1 \\
21\end{array}$ \\
\hline Total & 170 & 148 & 22 \\
\hline
\end{tabular}

atrial fibrillation recurred within 24 hours, and in 9 of these sinus rhythm persisted only for a few seconds to a few minutes. Of the 58 patients who after atrial defibrillation are known to be still in sinus rhythm at the time of writing, 24 have so far maintained sinus rhythm for 1 month, 27 between 1 and 6 months, 5 between 6 and 12 months, 1 for 13 , and 1 for 14 months.

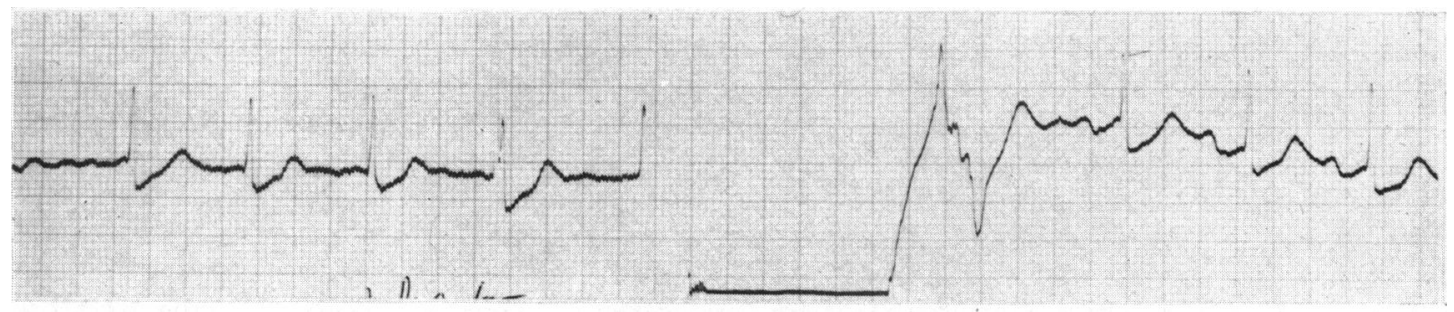

Fig. 1.-Atrial fibrillation converted to sinus rhythm by direct current shock.

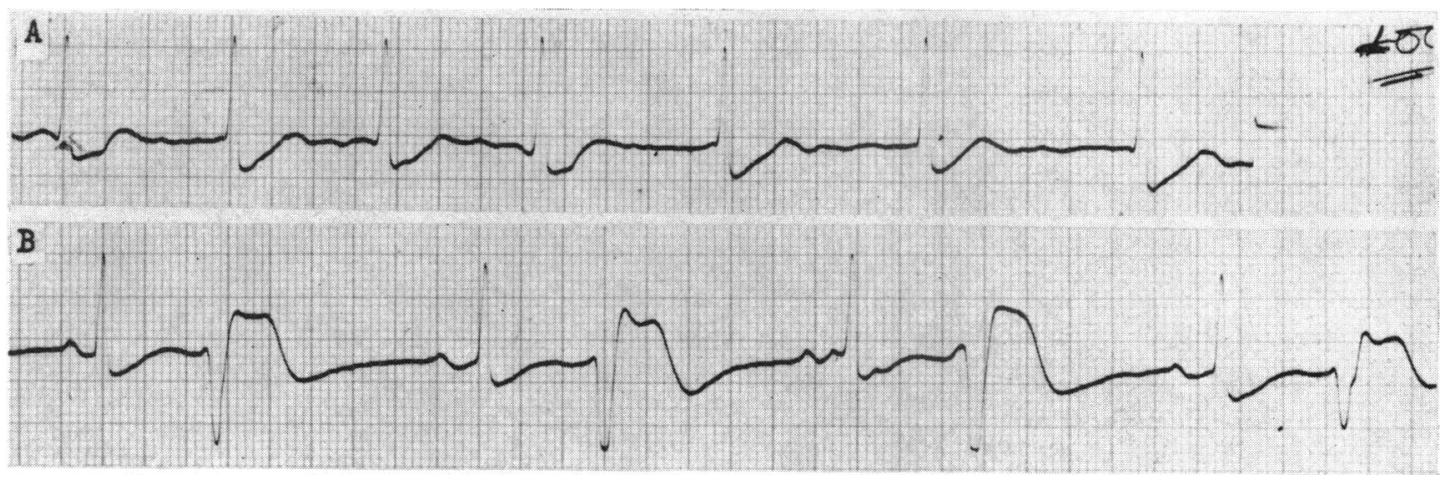

Fig. 2.-(A) Atrial fibrillation treated by direct current shock.

(B) Sinus rhythm with extrasystolic bigeminy immediately after conversion. 
TABLE III

ATRIAL DEFIBRILLATION BY DIRECT CURRENT SHOCK THERAPY RECURRENCE OF ATRIAL FIBRILLATION

\begin{tabular}{|c|c|c|c|c|c|c|c|}
\hline \multirow{2}{*}{$\begin{array}{l}\text { Duration of } \\
\text { atrial fibrillation } \\
\text { before treatment }\end{array}$} & \multirow{2}{*}{$\begin{array}{l}\text { Sinus rhythm } \\
\text { restored } \\
\text { No. of cases }\end{array}$} & \multicolumn{5}{|c|}{ Recurrences } & \multirow[t]{2}{*}{ Total } \\
\hline & & 24 hours & 1-7 days & 1-4 weeks & 1-6 months & 6-12 months & \\
\hline $\begin{array}{l}<1 \text { year } \\
>1 \text { year }\end{array}$ & $\begin{array}{l}59 \\
89\end{array}$ & 22 & $\begin{array}{l}5 \\
8\end{array}$ & $\begin{array}{r}7 \\
21\end{array}$ & $\begin{array}{r}2 \\
12\end{array}$ & $\begin{array}{l}4 \\
7\end{array}$ & $\begin{array}{l}20 \\
70\end{array}$ \\
\hline Total & 148 & $\begin{array}{c}24 \\
(16 \%)\end{array}$ & $\begin{array}{c}13 \\
(8.5 \%)\end{array}$ & $\begin{array}{c}28 \\
(19 \%)\end{array}$ & $\begin{array}{c}13 \\
(9.5 \%)\end{array}$ & $\begin{array}{c}11 \\
(7 \%)\end{array}$ & $\begin{array}{c}90 \\
(60 \%)\end{array}$ \\
\hline
\end{tabular}

Atrial Flutter. Fifteen episodes were treated in 13 patients and sinus rhythm was restored on all 15 occasions. Two patients had rheumatic heart disease, 5 coronary artery disease, 1 congenital heart disease, 1 thyrotoxicosis, and in 4 the nature of the underlying cardiac pathology was uncertain. The average age of the patients was 52 years. The arrhythmia recurred in 3 instances: twice in the same patient with coronary disease and once in a 52-year-old patient in whom an atrial septal defect was closed 5 years before (Fig. 3).
Atrial Tachycardia. Nine episodes were treated in 6 patients and sinus rhythm was restored in all 9 instances. Three patients had rheumatic heart disease, 2 had congenital heart disease, and in 1 no underlying pathology was found. There were 3 recurrences, all of which occurred in a 37-year-old woman who in 1958 had a mitral valvotomy resulting in atrial fibrillation. Attempts to restore sinus rhythm with quinidine and procaine amide were unsuccessful, but 5 years later she reverted to sinus rhythm spontaneously. Six months after this she started

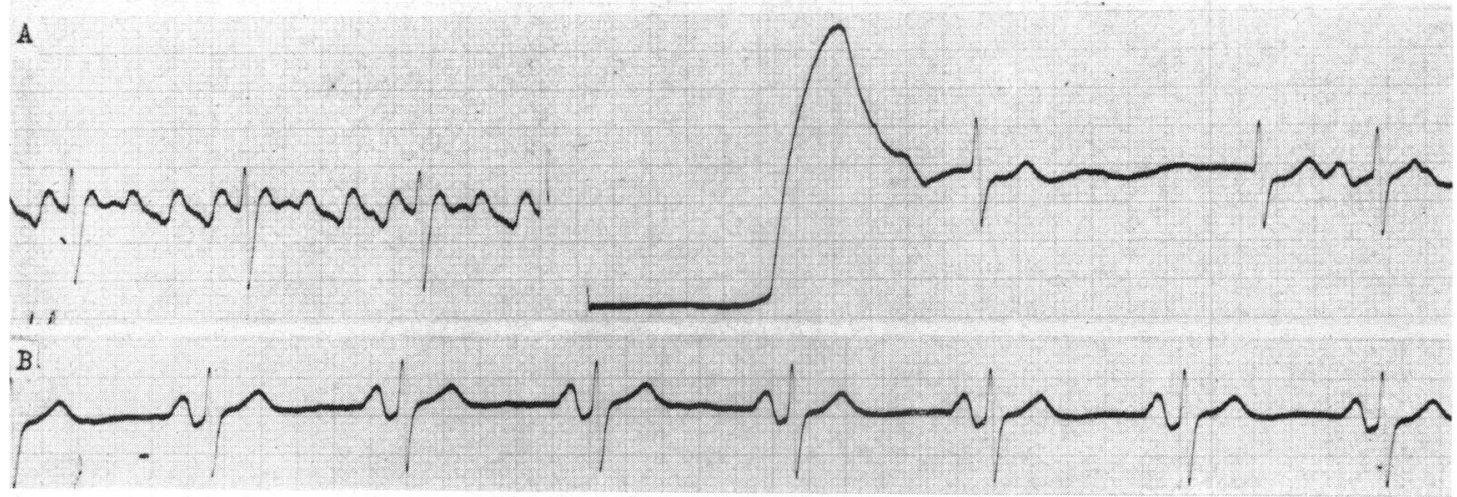

Fig. 3.-(A) Atrial flutter treated by direct current shock.

(B) Regular sinus rhythm 30 seconds later.

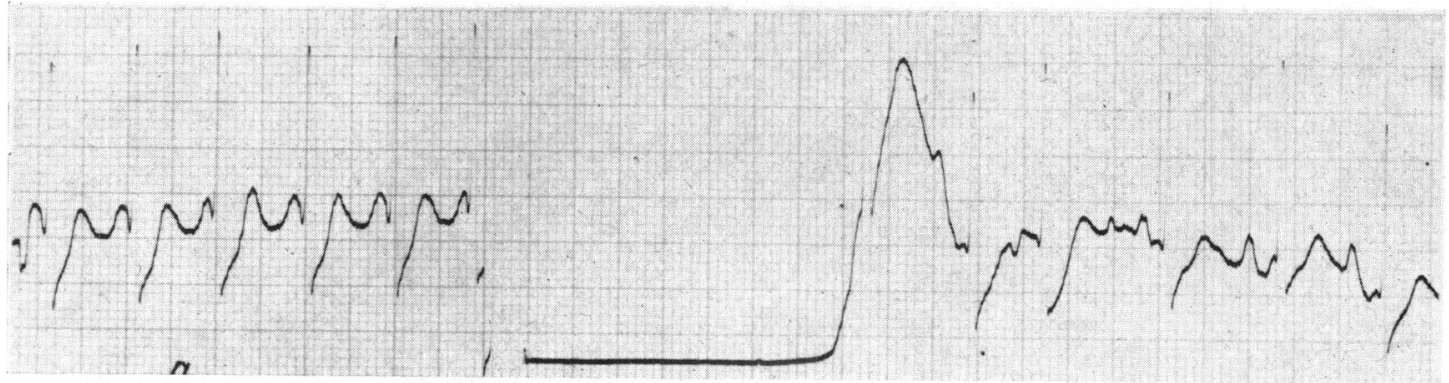

Fig. 4.-Atrial tachycardia. Sinus rhythm restored by direct current shock. 

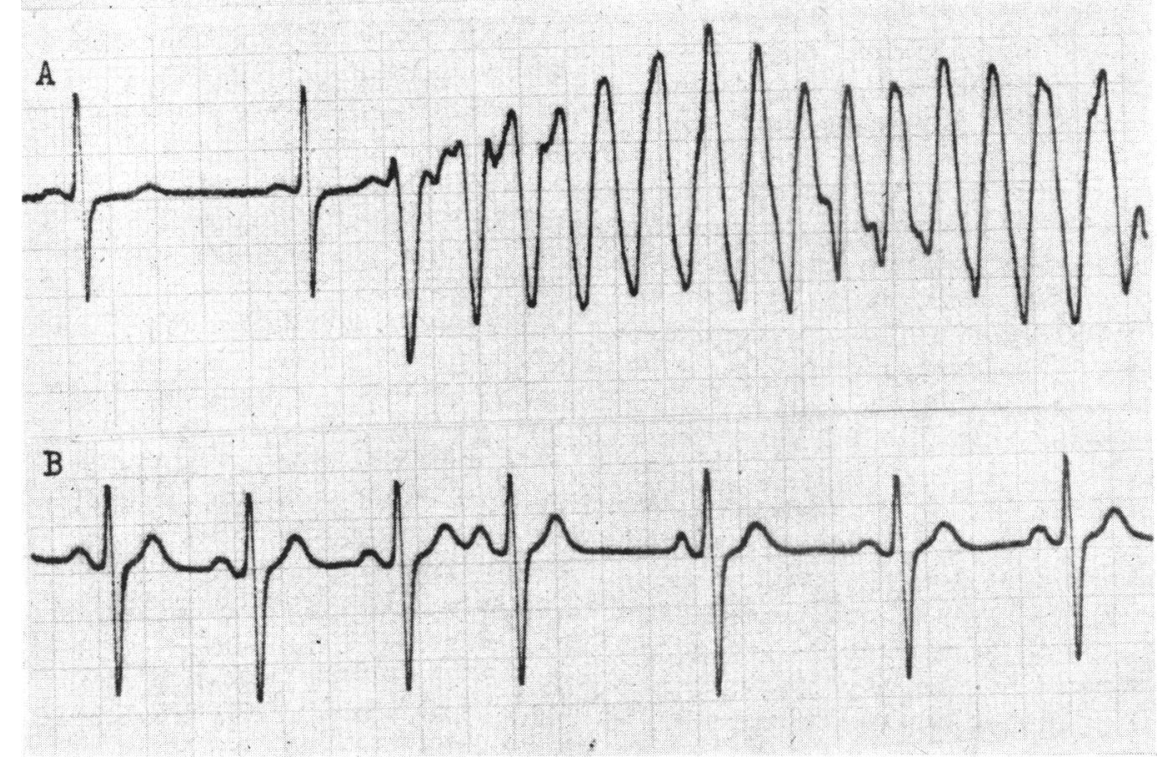

Fig. 5.-(A) Onset of ventricular tachycardia during angiocardiography.

(B) Sinus rhythm after direct current shock therapy.

having attacks of supraventricular tachycardia which did not respond to drug therapy, but were readily controlled by direct current shock (Fig. 4).

Ventricular Tachycardia. Four patients have undergone treatment. In 3 normal sinus rhythm was restored, and in the fourth atrial tachycardia appeared which was then stopped by procaine amide. Two patients had recent cardiac infarction, 1 had no detectable cardiac pathology, and the fourth patient developed ventricular tachycardia with transient episodes of ventricular fibrillation during an angiocardiographic investigation for suspected obstructive cardiomyopathy. Fig. 5 shows an episode of ventricular tachycardia terminated by direct current shock.

Ventricular Fibrillation. Two patients with ventricular fibrillation were defibrillated. Both patients had extensive cardiac infarction and died despite the restoration of normal rhythm (Fig. 6) and other resuscitative measures.

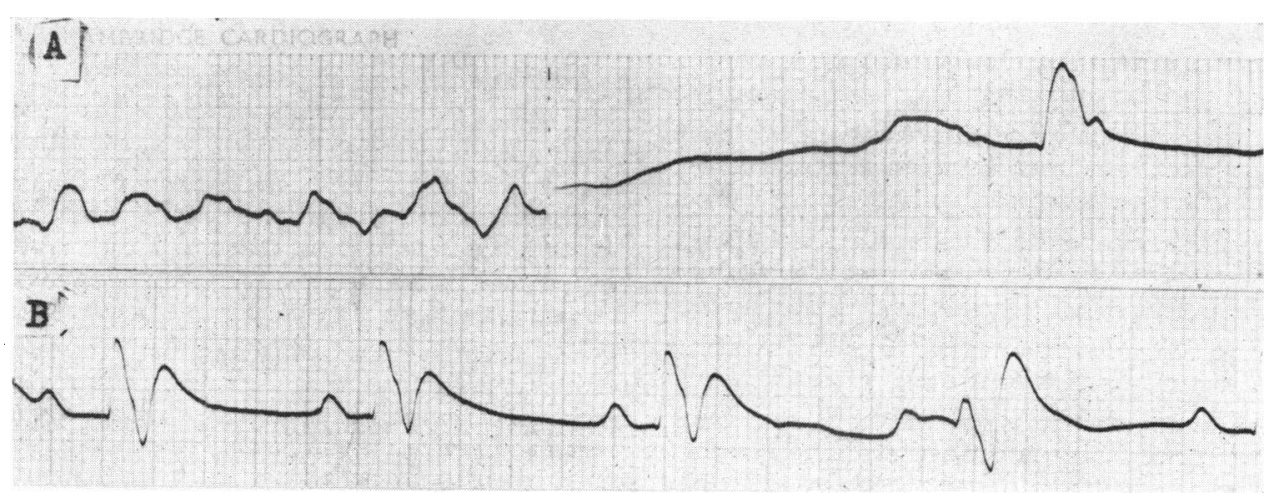

Fig. 6.-(A) Ventricular fibrillation complicating acute cardiac infarction.

(B) Sinus rhythm after defibrillation. 


\section{Discussion}

The majority of our patients treated by direct current shock had atrial fibrillation as shown in Table I. Sinus rhythm was restored in 87 per cent of the cases. These results are similar to those obtained in large series by previous workers (Killip, 1963; Lown, 1964; Oram and Davies, 1964; McDonald et al., 1964; Pantridge and Halmos, 1965), and it is now generally accepted that they are superior to those achieved by the use of antiarrhythmic drugs alone. The immediate results seem to be influenced by the duration of atrial fibrillation. Thus Pantridge and Halmos (1965) found that the average duration of atrial fibrillation was 35.7 months in patients who were converted and 81 months in those in whom sinus rhythm could not be restored. Our own observations are in agreement with these findings. In our experience, the age of the patient did not seem to have a direct influence on the results. On the other hand, Oram and Davies (1964) stated that patients under 50 showed a better result than those over 50 .

Recurrence of atrial fibrillation was common in all published studies in spite of the prophylactic use of antiarrhythmic drugs. In our own series, the recurrence rate was 60 per cent over a follow-up period of up to 15 months. In 10 per cent of the total recurrences, atrial fibrillation reappeared after a few minutes. Killip (1963) postulated in this type of case an inability of the sinus node to maintain its pacemaker activity owing to disease or druginduced depression. We found early recurrence of atrial fibrillation especially in those patients who showed immediately after conversion frequent atrial or ventricular extrasystoles, an unstable pacemaker, or marked prolongation of the atrio-ventricular conduction time. These observations correspond to those of Lown et al. (1963), Lemberg et al. (1964), and Morris et al. (1964). In the rheumatic group the recurrence rate was higher in the presence of significant mitral regurgitation than in pure mitral stenosis. Morris et al. (1964) have also found that maintenance of sinus rhythm was more successful in pure mitral stenosis than in mitral regurgitation. However, when our patients with rheumatic heart disease in whom atrial defibrillation was successfully accomplished were grouped into those who had already had a mitral valve operation and those who had not, the recurrence rate of atrial fibrillation proved to be identical in both groups.

The value of conventional prophylactic doses of antiarrhythmic agents in the prevention of recurrences of atrial fibrillation remains questionable. We used quinidine ( $1 \mathrm{~g}$. daily), procaine amide ( $3 \mathrm{~g}$. daily), and propranolol (30 mg. daily), given singly or in combination. The recurrence rate was practically identical in each of these groups and only slightly less than in the very small group of patients who did not have antiarrhythmic drugs at all or discontinued them. It is possible that significantly larger doses would be more effective in preventing recurrences, but the administration of such doses over a longer period could lead to practical difficulties concerning side-effects and safety. We are now engaged in a second trial using larger doses of propranolol.

All published reports as well as our own observations show that direct current shock therapy is also very effective in terminating attacks of atrial tachycardia, atrial flutter, and ventricular tachycardia. However, in the light of present experience special caution may be needed in the presence of digitalis-induced ectopic tachycardias.

Various transient arrhythmias occurring immediately after direct current shock have been reported by several workers (Lemberg et al., 1964; Lown, 1964; McDonald et al., 1964; Oram and Davies, 1964). In our series, atrial extrasystoles occurred in 10 per cent of the cases, ventricular extrasystoles in 28 per cent with a bigeminal pattern in nearly half of these, atrial tachycardia in 11 per cent, ventricular tachycardia of very short duration in 8 per cent, prolonged atrio-ventricular conduction in 12 per cent, and nodal rhythm in 8 per cent of the cases. Partial atrio-ventricular block or complete atrio-ventricular dissociation was observed only very occasionally. However, these arrhythmias occurred much less frequently in the last 78 cases when the digitalis dose was reduced three to five days before electrical treatment. Lown (1964) has suggested that the incidence of post-conversion arrhythmias can be reduced if digitalis is omitted for at least 24 hours before shock treatment. He also advised correction of electrolyte deficit, especially potassium depletion. The influence of digitalis on the immediate results of counter-shock therapy and on the occurrence of post-conversion arrhythmias is yet to be clarified. Jouve et al. (1963) found that previous digitalis treatment increased the chances of success in converting atrial fibrillation or flutter to sinus rhythm. On the other hand, Pantridge and Halmos (1965) believe that overdigitalization may be responsible for the failure of the sinus pacemaker to resume its activity. Gilbert and Cuddy (1964) postulate that digitalis intoxication may become manifest in sinus rhythm when not evident in atrial fibrillation. They further raise the possibility that direct current shock may potentiate the toxic effects of digitalis. Our own experimental studies, though still in their initial stages, do indeed suggest such a potentiation possibly due to transient cellular 
damage resulting from the direct current shock. We have also observed in these experiments that direct current shock occasionally transformed digitalisinduced ventricular tachycardia into ventricular fibrillation. Fatal ventricular fibrillation thought to be due to digitalis excess has been reported following direct current shock therapy of arrhythmias (Rabbino, Likoff, and Dreifus, 1964; Robinson and Wagner, 1965). On the other hand, Corwin, Klein, and Friedberg (1963) succeeded in restoring sinus rhythm by direct current shock in a patient exhibiting atrial tachycardia with block probably caused by digitalis. Further experience is needed in this particular aspect of direct current shock therapy.

Post-conversion arrhythmias have also been observed more frequently when large watt-second values were used (Castellanos et al., 1964; Lown, 1964). On the other hand, Mathivat, Clément, and Allard (1965) found no relation between the incidence of post-conversion arrhythmias and the watt-second values given. It should be emphasized in this connexion that too low energy capacitor discharges can lead to incomplete depolarization of the myocardium and thus produce ventricular tachycardia or fibrillation more readily than high energy discharges (Effert and Grosse-Brockhoff, 1963; Graf and Etkins, 1964).

Systemic embolism following cardioversion has occasionally been observed (Effert and GrosseBrockhoff, 1963; Jouve et al., 1963; Brown et al., 1964; Graf and Etkins, 1964; Lown, 1964; Rabbino et al., 1964). One of these patients was receiving anticoagulants (Graf and Etkins, 1964). One of our patients, a 64-year-old man with coronary artery disease, developed a transient hemiparesis, presumably due to a cerebral embolus, 22 hours after atrial defibrillation. $\mathrm{He}$ was not receiving anticoagulant prophylaxis. The place of anticoagulant prophylaxis in association with cardioversion is still unresolved. Oram and Davies (1964) used anticoagulant therapy only in patients with recent onset of atrial fibrillation, a history of embolism, mitral stenosis, or a large heart. McDonald et al. (1964) believe that anticoagulant cover should be given to all patients where there is a substantial risk of embolism. Pantridge and Halmos (1965) feel that anticoagulant treatment is unnecessary. Lown (1964) draws attention to the fact that embolism during or after quinidine conversion of atrial fibrillation does not occur in more than 2

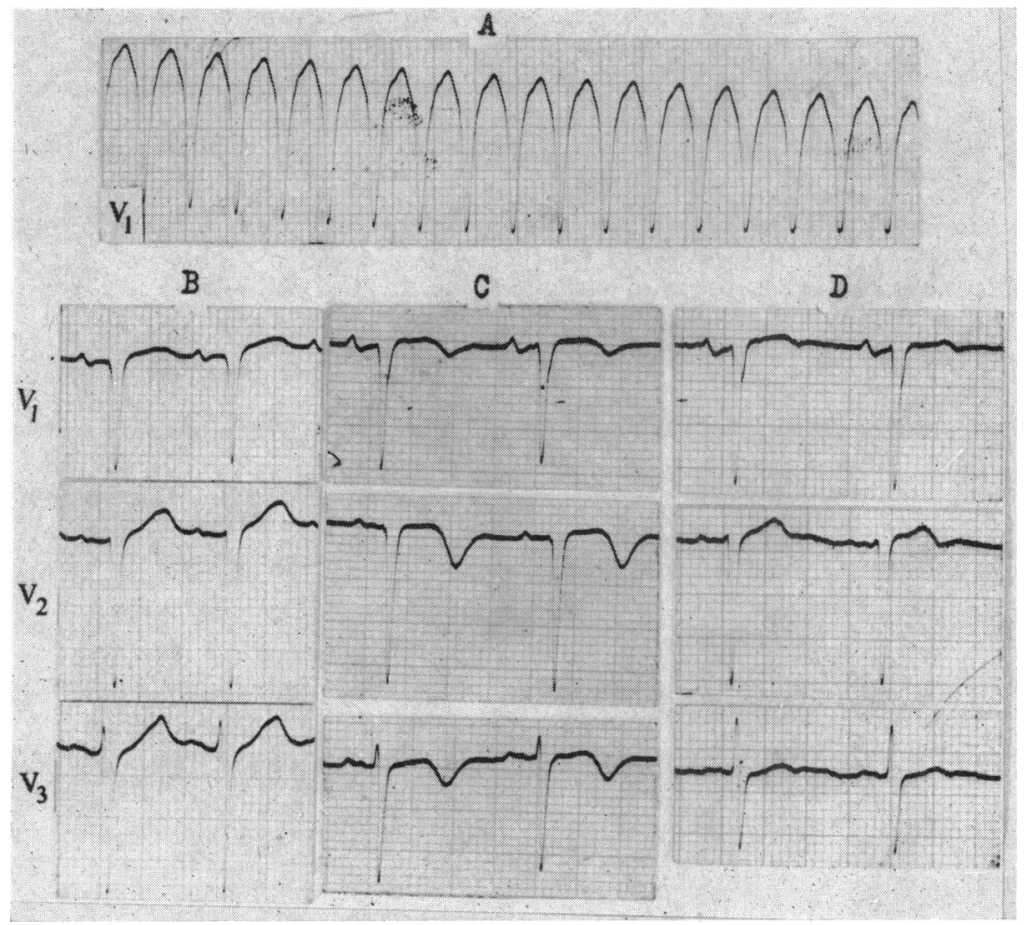

Fig. 7.-(A) Ventricular tachycardia.

(B) Immediately after restoration of sinus rhythm by direct current shock. Upright T waves in V 1-3.

(C) Inverted $T$ waves 3 days later.

(D) 4 days after (C), $\mathrm{T}$ waves upright again. 
per cent of the patients, and he finds it difficult to establish precise criteria for the use of such prophylactic measures.

Transient changes in the S-T segment and/or in the $T$ wave indicative of myocardial injury, with or without a rise in the transaminase levels, have occasionally been observed (Killip, 1963; McDonald et al., 1964; Oram and Davies, 1964; Sussman, Woldenberg, and Cohen, 1964; Turner and Towers, 1964). In 2 of our patients, electrocardiographic changes appeared after direct current shock therapy suggestive of a limited cardiac infarction, and in one of these the transaminase level rose to $220 \mathrm{u}$. $/ \mathrm{ml}$. (Fig. 7). In 5 other patients a current of injury appeared but it disappeared after a few seconds. Recently, Resnekov and McDonald (1965) reported 4 patients who developed acute pulmonary œdema after the restoration of sinus rhythm, but we have not met this complication.

It appears from the results of other workers and from our own observations that ectopic tachycardias, both atrial and ventricular, constitute an indication for direct current shock therapy, but that special caution may be necessary in digitalis-induced tachycardias. Because of the high recurrence rate in atrial fibrillation, some selection needs to be exercised in this group. In many non-urgent instances conventional drug therapy will still remain the first line of approach.

\section{SUMMARY}

The results of direct current shock therapy of 200 episodes of cardiac arrhythmia are reported. Such treatment was given in $\mathbf{1 7 0}$ episodes of atrial fibrillation, 15 of atrial flutter, 9 of atrial tachycardia, 4 episodes of ventricular tachycardia, and 2 of ventricular fibrillation.

In atrial fibrillation, sinus rhythm was restored in 87 per cent of the cases. The recurrence rate over a follow-up period of up to 15 months was 60 per cent, in spite of drug prophylaxis.

Direct current shock therapy was successful in all cases of atrial tachycardia and atrial flutter, and in 3 out of 4 cases of ventricular tachycardia.

One episode of systemic embolism followed the conversion of atrial fibrillation to sinus rhythm in a patient not receiving anticoagulants, but the place of anticoagulant prophylaxis in relation to cardioversion has yet to be clarified.

Transient S-T segment elevation occurred in 5 patients after direct current shock therapy, and gross $T$ wave inversion considered to be due to cardiac infarction in 2.

We should like to thank Dr. S. Oram who kindly acquainted one of us (P.S.) with the technique of cardio- version. Our thanks are also due to Drs. Swan, Jackson, and Henderson for allowing us to include their patients in this study, and to Mr. D. Roberts and Miss V. Jones for technical assistance. We are greatly obliged to a private benefactor who generously provided the apparatus, and to Imperial Chemical Industries Ltd., Pharmaceuticals Division, for the supply of propranolol.

\section{REFERENCES}

Bouvrain, Y., Guedon, J., Slama, R., and Naouri, R. (1963). Traitement de la tachycardie ventriculaire par choc électrique externe. Presse méd., 71, 2379.

Brown, K. W. G., Whitehead, E. H., and Morrow, J. D. (1964). Treatment of cardiac arrhythmias with synchronized electrical countershock. Canad. med. Ass. F., 90, 103.

Castellanos, A., Fonseca, E. J., Gosselin, A., and Lemberg, L. (1964). Ventricular arrhythmias induced by directcurrent countershock (abstract). Circulation, 30, Suppl. III, p. 59.

Corwin, N. D., Klein, M. J., and Friedberg, C. K. (1963). Countershock conversion of digitalis-associated paroxysmal atrial tachycardia with block. Amer. Heart f., 66, 804.

Effert, S., and Grosse-Brockhoff, F. (1963). Elektrotherapie der Herzrhythmusstörungen. Dtsch. med. Wschr., 88, 2165.

Gilbert, R., and Cuddy, R. P. (1964). Digitalis intoxication following conversion to sinus rhythm (abstract). Circulation, 30, Suppl. III, p. 83.

Graf, W. S., and Etkins, P. (1964). Ventricular tachycardia after synchronized direct-current countershock. $\mathcal{F}$. Amer. med. Ass., 190, 470.

Jouve, A., Torresani, J., Delaage, M., and Fran çois, G. (1963). Traitement des tachycardies par chocs électriques externes. Arch. Mal. Cour, 56, 1078.

Killip, T. (1963). Synchronized DC precordial shock for arrhythmias. f. Amer. med. Ass., 186, 1.

Kuhn, L. A. (1964). Electrical conversion of arrhythmias. Amer. Heart F., 67, 709.

Lemberg, L., Castellanos, A., Swenson, J., and Gosselin, A. (1964). Arrhythmias related to cardioversion. Circulation, 30, 163.

Lown, B. (1964). "Cardioversion" of arrhythmias. Mod. Conc. cardiovasc. Dis., 33, 863 and 869.

- Amarasingham, R., and Neuman, J. (1962). New method for terminating cardiac arrhythmias. f. Amer. med. Ass., 182, 548.

—, Kaid Bey, S., Perlroth, M. G., and Abe, T. (1963). Cardioversion of ectopic tachycardias. Amer. $\mathcal{f}$. med. Sci., 246, 257.

-, Kleiger, R., and Wolff, G. (1964). The technique of cardioversion. Amer. Heart F., 67, 282.

McDonald, L., Resnekov, L. and O'Brien, K. (1964). Directcurrent shock in treatment of drug-resistant cardiac arrhythmias. Brit. med. $\mathcal{F}$., 1, 1468.

Mathivat, A., Clément, D., and Allard, P. (1965). Aspects de l'électrocardiogramme au cours du traitement de la fibrillation et du flutter auriculaires par les chocs électriques externes à courant direct. Arch. Mal. Cour, 58, 218.

- - Legendre, M., Rosenthal, D., Marie-Louise, C., and Jouandou, J. (1964). Le choc électrique externe par décharge de condensateur (courant direct), dans le traitement de 100 cas de tachycardies ectopiques. Arch. Mal. Cour, 57, 372. 
Morris, J. J., Jr., Kong, Y., North, W. C., and McIntosh, H. D. (1964). Experience with "cardioversion" of atrial fibrillation and flutter. Amer. f. Cardiol., 14, 94.

Oram, S., and Davies, J. P. H. (1964). Further experience of electrical conversion of atrial fibrillation to sinus rhythm: analysis of 100 patients. Lancet, 1, 1294.

$\longrightarrow,-\longrightarrow$ Weinbren, I., Taggart, P., and Kitchen, L. D. (1963). Conversion of atrial fibrillation to sinus rhythm by direct-current shock. Lancet, 2, 159.

Pantridge, J. F., and Halmos, P. B. (1965). Conversion of atrial fibrillation by direct current counter shock. Brit. Heart F., 27, 128.

Rabbino, M. D., Likoff, W., and Dreifus, L. S. (1964). Complications and limitations of direct-current countershock. F. Amer. med. Ass., 190, 417.
Reitman, N., and DeArmas, D. (1963). Refractory ventricular tachycardia terminated by electric countershock. Amer. F. Cardiol., 12, 860.

Resnekov, L., and McDonald, L. (1965). Pulmonary oedema following treatment of arrhythmias by direct-current shock. Lancet, 1, 506.

Robinson, H. J., and Wagner, J. A. (1965). D. C. cardioversion causing ventricular fibrillation. Amer. F. med. Sci., 249, 300.

Sussman, R. M., Woldenberg, D., and Cohen, M. (1964). Myocardial changes immediately following direct current shock for termination of atrial fibrillation. Abstracts, 7th Inter-American Congress of Cardiology, Montreal, p. 166.

Turner, J. R. B., and Towers, J. R. H. (1964). Myocardial damage from therapeutic electric shock. Lancet, 1 , 1396. 